\title{
Correction to: Fecal Microbiota Transplantation Capsules with Targeted Colonic Versus Gastric Delivery in Recurrent Clostridium difficile Infection: A Comparative Cohort Analysis of High and Low Dose
}

Jessica R. Allegretti ${ }^{1,2} \cdot$ Monika Fischer $^{3} \cdot$ Sashidhar V. Sagi $^{3} \cdot$ Matthew E. Bohm ${ }^{3} \cdot$ Hala M. Fadda $^{4} \cdot$ Sejal R. Ranmal ${ }^{8}$. Shrish Budree ${ }^{5,6} \cdot$ Abdul W. Basit $^{8,9}$. Dean L. Glettig ${ }^{7}$ - Eva L. de la Serna ${ }^{7}$. Amanda Gentile ${ }^{7}$. Ylaine Gerardin ${ }^{7}$. Sonia Timberlake ${ }^{7} \cdot$ Rotem Sadovsky $^{7} \cdot$ Mark Smith $^{7} \cdot$ Zain Kassam $^{7}$

Published online: 18 February 2019

(c) Springer Science+Business Media, LLC, part of Springer Nature 2019

\section{Correction to: Digestive Diseases and Sciences}

https://doi.org/10.1007/s10620-018-5396-6

The original version of the article unfortunately contained an error in article title. The corrected title is 'Fecal Microbiota Transplantation Capsules with Targeted Colonic Versus Gastric Delivery in Recurrent Clostridium difficile Infection: A Comparative Cohort Analysis of High and Low Dose'.

The original article can be found online at https://doi.org/10.1007/ s10620-018-5396-6.

Jessica R. Allegretti

jallegretti@partners.org

1 Division of Gastroenterology, Hepatology and Endoscopy, Brigham and Women's Hospital, 75 Francis Street, Boston, MA 02115, USA

2 Harvard Medical School, Boston, MA, USA

3 Division of Gastroenterology, Indiana University, Indianapolis, IN, USA

4 College of Pharmacy and Health Sciences, Butler University, Indianapolis, IN, USA

5 OpenBiome, Somerville, MA, USA

6 University of Cape Town, Cape Town, South Africa

7 Finch Therapeutics, Somerville, MA, USA

8 Intract Pharma, London, UK

9 School of Pharmacy, University College London, London, UK 